\title{
Diffusive Formation of Hollow Mesoporous Silica Shells from Core- Shell Composites: Insights from the Hydrogen Sulfide Capture Cycle of $\mathrm{CuO} @ \mathrm{mSiO}_{2}$ Nanoparticles
}

Baoyue Fan, ${ }^{\mathrm{a}}$ Wenyang Zhao, ${ }^{\mathrm{a}}$ Supriya Ghosh, ${ }^{\mathrm{b}} \mathrm{K}$. Andre Mkhoyan, ${ }^{\mathrm{b}}$ Michael Tsapatsis,,${ }^{\mathrm{c}}{ }^{*}$ Andreas Stein ${ }^{\mathrm{a}, *}$

${ }^{a}$ Department of Chemistry, University of Minnesota, Minneapolis, MN 55455, USA

${ }^{b}$ Department of Chemical Engineering \& Materials Science, University of Minnesota, Minneapolis, Minnesota 55455, USA

${ }^{c}$ Department of Chemical and Biomolecular Engineering \& Institute for NanoBioTechnology, Johns Hopkins University, MD 21218, USA

*E-mail: tsapatsis@jhu.edu (M.T.)

*E-mail: a-stein@umn.edu (A.S.)

Number of pages: 11

Number of figures: 13 


\section{Table of Contents}

Figure S1. Experimental set-up for the in-situ sulfidation reaction.

Figure S2. Illustration of extensive grain growth when a CuO-based $\mathrm{H}_{2} \mathrm{~S}$ sorbent is sulfidated and regenerated over multiple cycles.

Figure S3. TEM images of $\mathrm{CuO} @ \mathrm{mSiO}_{2}-\mathrm{N}$-calcined.

Figure S4. Distributions of the thickness of silica shells and of particle widths.

Figure S5. XRD pattern of $\mathrm{CuO} @ \mathrm{mSiO}_{2}-\mathrm{N}$.

Figure S6. Powder XRD patterns of $\mathrm{CuO} @ \mathrm{mSiO}_{2}-\mathrm{N}$ before and after calcination in air at $350{ }^{\circ} \mathrm{C}$ and of the sulfided material $\mathrm{CuS} @ \mathrm{mSiO}_{2}-\mathrm{N}$.

Figure S7. Distributions of core widths of (a) $\mathrm{CuO} @ \mathrm{mSiO}_{2}-\mathrm{N}$-calcined and

(b) $\mathrm{CuS} @ \mathrm{mSiO}_{2}-\mathrm{N}$ particles.

Figure S8. (a) HAADF-STEM image of $\mathrm{CuO} / \mathrm{HmSiO}_{2}-\mathrm{N} 2$ and (b) the corresponding STEM-EDS elemental map for sulfur.

Figure S9. Distribution of the thickness of silica shells of $\mathrm{CuS} @ \mathrm{mSiO}_{2}-\mathrm{D}$ particles.

Figure S10. FTIR spectrum of $\mathrm{CuS} @ \mathrm{mSiO}_{2}-\mathrm{D}$.

Figure S11. XRD pattern of $\mathrm{CuS} @ \mathrm{mSiO}_{2}-\mathrm{D}$.

Figure S12. (a) TEM image and (b) SAED pattern of an irregularly-shaped phase observed in the sample $\mathrm{CuS} @ \mathrm{mSiO}_{2}-\mathrm{D}-350$. 


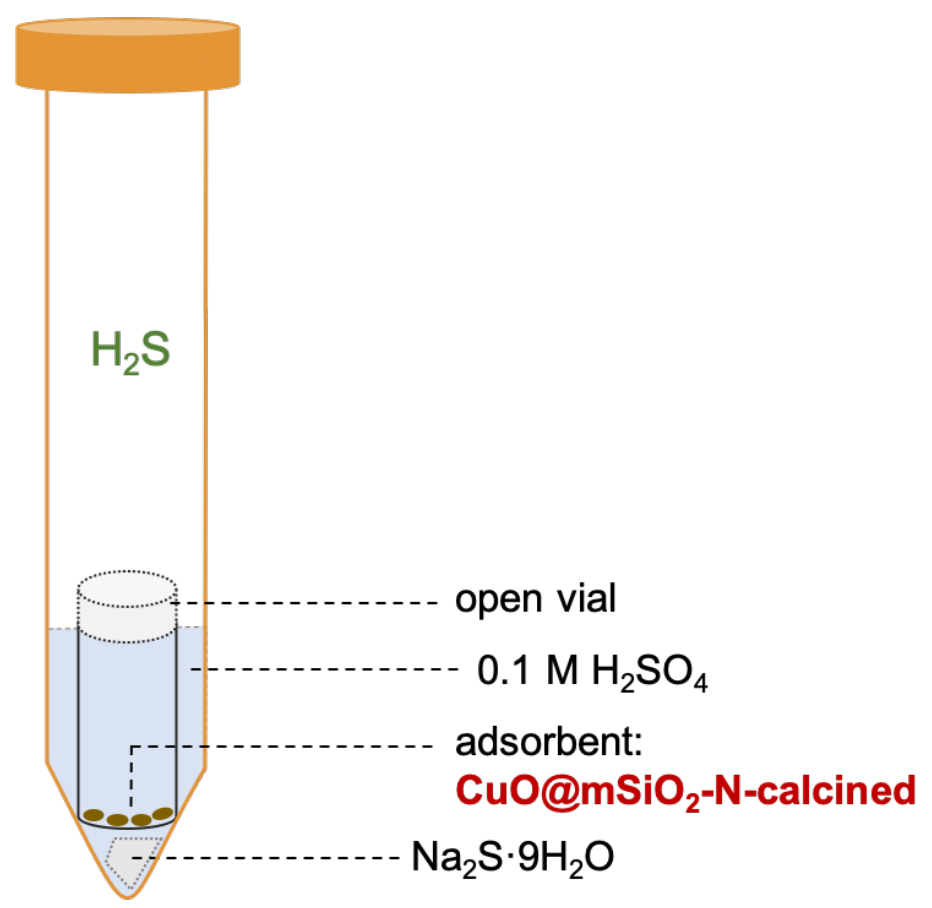

Figure S1. Experimental set-up for the in-situ sulfidation reaction. The inner open vial contained only the adsorbent. $\mathrm{H}_{2} \mathrm{SO}_{4}$ solution was carefully pipetted into the centrifuge tube, but only on the outside of the open vial. (Caution: avoid sulfuric acid solution from entering into the vial, which would dissolve the adsorbent particles.) 


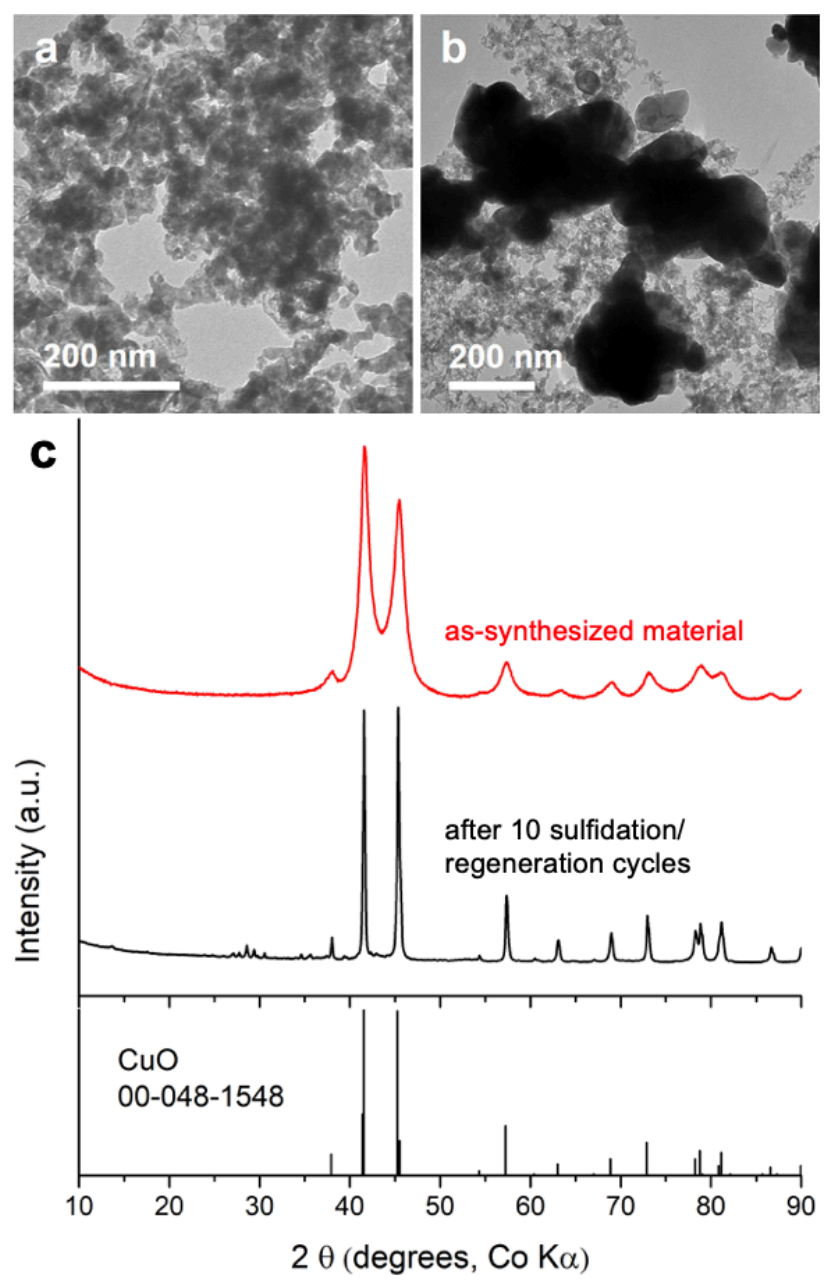

Figure S2. Illustration of extensive grain growth when a CuO-based $\mathrm{H}_{2} \mathrm{~S}$ sorbent is sulfidated and regenerated over multiple cycles. (a) TEM image of the as-synthesized absorbent with an approximate composition of $50 \mathrm{CuO} \cdot \mathrm{MgO} \cdot 3.5 \mathrm{Al}_{2} \mathrm{O}_{3}$ estimated from energy dispersive X-ray spectroscopy and electron-energy-loss spectra. (b) TEM image of this sample after ten sulfidation and regeneration cycles. Significant growth of $\mathrm{CuO}$ grains has occurred. (c) Powder XRD patterns of these samples. The estimated CuO grain size increased from $15 \mathrm{~nm}$ to $90 \mathrm{~nm}$ after ten sulfidation/regeneration cycles, estimated on the basis of Scherrer line broadening. The sample was synthesized from a $50-\mathrm{mL}$ mixture solution containing $30 \mathrm{~mL} 1.25 \mathrm{M} \mathrm{Cu}\left(\mathrm{NO}_{3}\right)_{2}, 15 \mathrm{~mL} 1.25 \mathrm{M} \mathrm{Mg}\left(\mathrm{NO}_{3}\right)_{2}$ and $5 \mathrm{~mL}$ $1.25 \mathrm{M} \mathrm{Al}\left(\mathrm{NO}_{3}\right)_{3}$. The mixed metal nitrate solution was added to a polypropylene bottle containing $100 \mathrm{~mL}$ deionized water heated at $70{ }^{\circ} \mathrm{C}$ in an oil bath at a rate of $5 \mathrm{~mL} / \mathrm{min}$ using a syringe infusion pump. The $\mathrm{pH}$ of the entire reaction mixture was maintained at 7 by manual in-situ addition of $1.25 \mathrm{M} \mathrm{Na}_{2} \mathrm{CO}_{3}$ solution. Upon complete addition of the mixed metal nitrate solution, the oil bath temperature was increased to $80^{\circ} \mathrm{C}$ and kept there for $1 \mathrm{~h}$ under stirring to age the mixture. The resulting precipitate was filtered and washed three times, each time with 2-L deionized water. The material was dried at $70^{\circ} \mathrm{C}$ for $12 \mathrm{~h}$ and then calcined at $500^{\circ} \mathrm{C}$ for $5 \mathrm{~h}$ in air flowing at a rate of $\sim 100 \mathrm{~mL} / \mathrm{min}$. The experimental set-up for sulfidation-regeneration studies was constructed from stainless steel 316 tubing and connections. $5.0 \mathrm{mg}$ of the sample (mesh 40-80) was diluted with $100.0 \mathrm{mg}$ of quartz (mesh 40-80) and sandwiched between quartz wool plugs in a U-shaped quartz tube with $4 \mathrm{~mm}$ inner diameter. Sorbent was activated in $40 \mathrm{~mL} / \mathrm{min}$ $\mathrm{N}_{2}$ flow at $300{ }^{\circ} \mathrm{C}$ for $12 \mathrm{~h}$ and then exposed to $\mathrm{H}_{2} \mathrm{~S}$ stream of $40 \mathrm{~mL} / \mathrm{min}\left(100 \mathrm{ppmv}\right.$ in $\left.\mathrm{N}_{2}\right)$ at $150^{\circ} \mathrm{C}$ and $1 \mathrm{~atm}$. The $\mathrm{H}_{2} \mathrm{~S}$ concentration at the reactor exit was monitored using a gas chromatograph (Agilent 7890A) equipped with a sulfur chemiluminescence detector (SCD). The sulfidated sorbent was regenerated by oxidation in the same reactor at $600{ }^{\circ} \mathrm{C}$ for $6 \mathrm{~h}$ in $5 \% \mathrm{O}_{2}$ (balanced with $\mathrm{N}_{2}$ ) flowing at a rate of $40 \mathrm{~mL} / \mathrm{min}$. The reactor was flushed with $\mathrm{N}_{2}$ for at least $15 \mathrm{~min}$ between cycles as a safety precaution. The sulfidation-regeneration was carried out for 10 cycles to obtain the $10^{\text {th }}$ regenerated sample. 

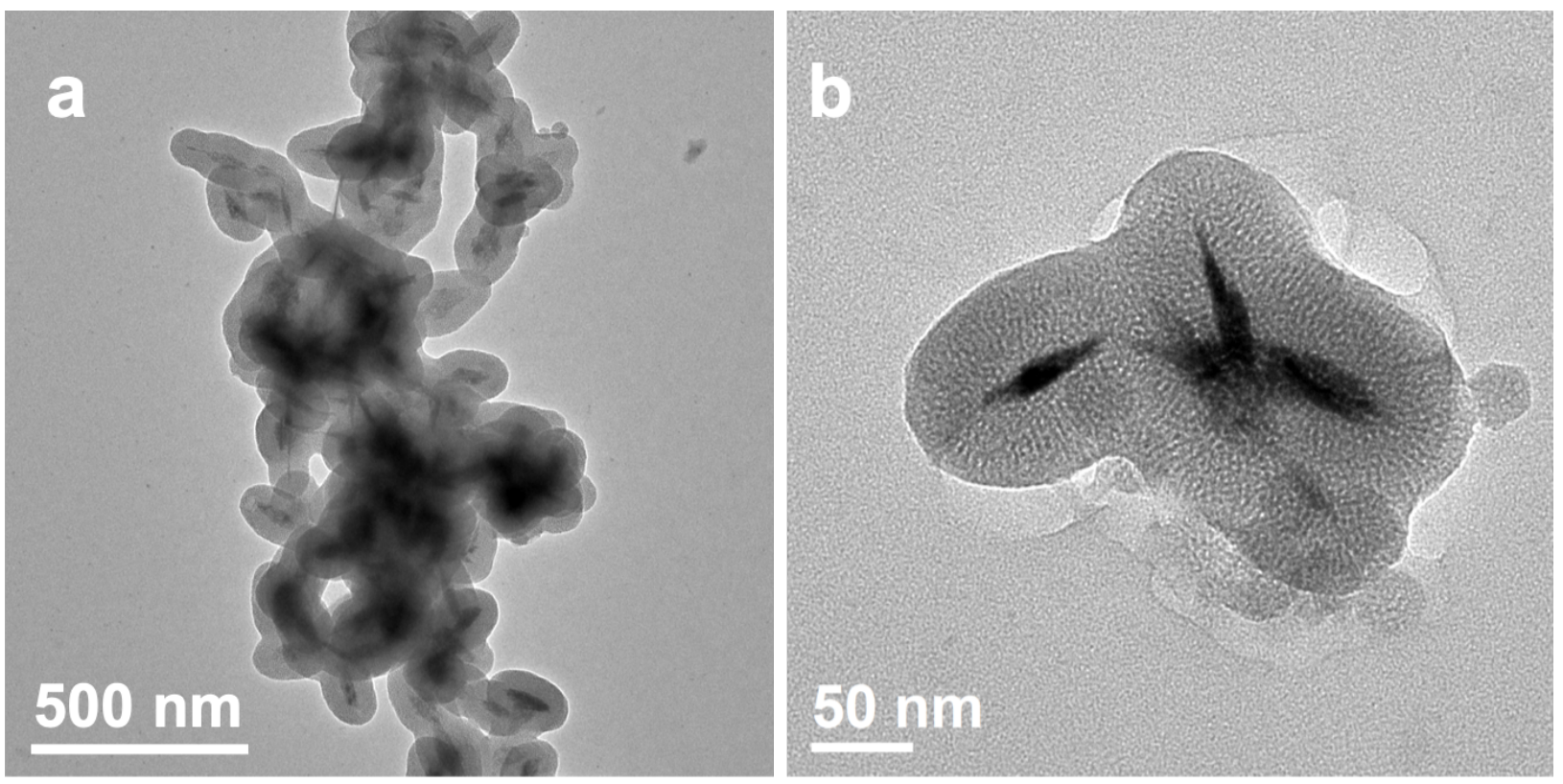

Figure S3. TEM images of $\mathrm{CuO} @ \mathrm{mSiO}_{2}-\mathrm{N}$-calcined. (a) and (b) show images at different magnifications.
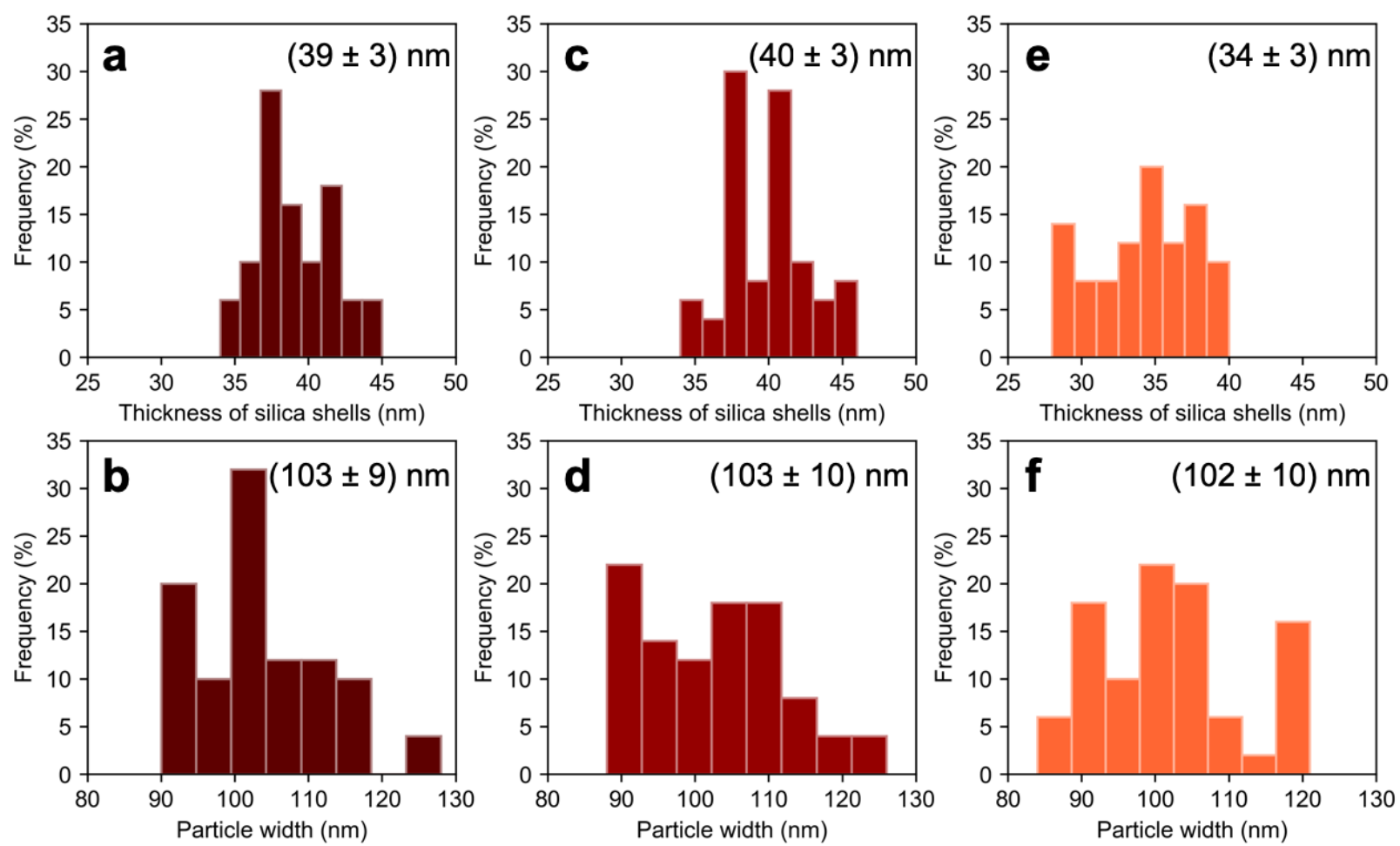

Figure S4. Distributions of the thickness of silica shells and of particle widths of (a, b) $\mathrm{CuO} @ \mathrm{mSiO}_{2}-\mathrm{N},(\mathrm{c}, \mathrm{d})$ $\mathrm{CuO} @ \mathrm{mSiO}_{2}-\mathrm{N}$-calcined and (e, f) $\mathrm{CuS} @ \mathrm{mSiO}_{2}-\mathrm{N}$ particles. 


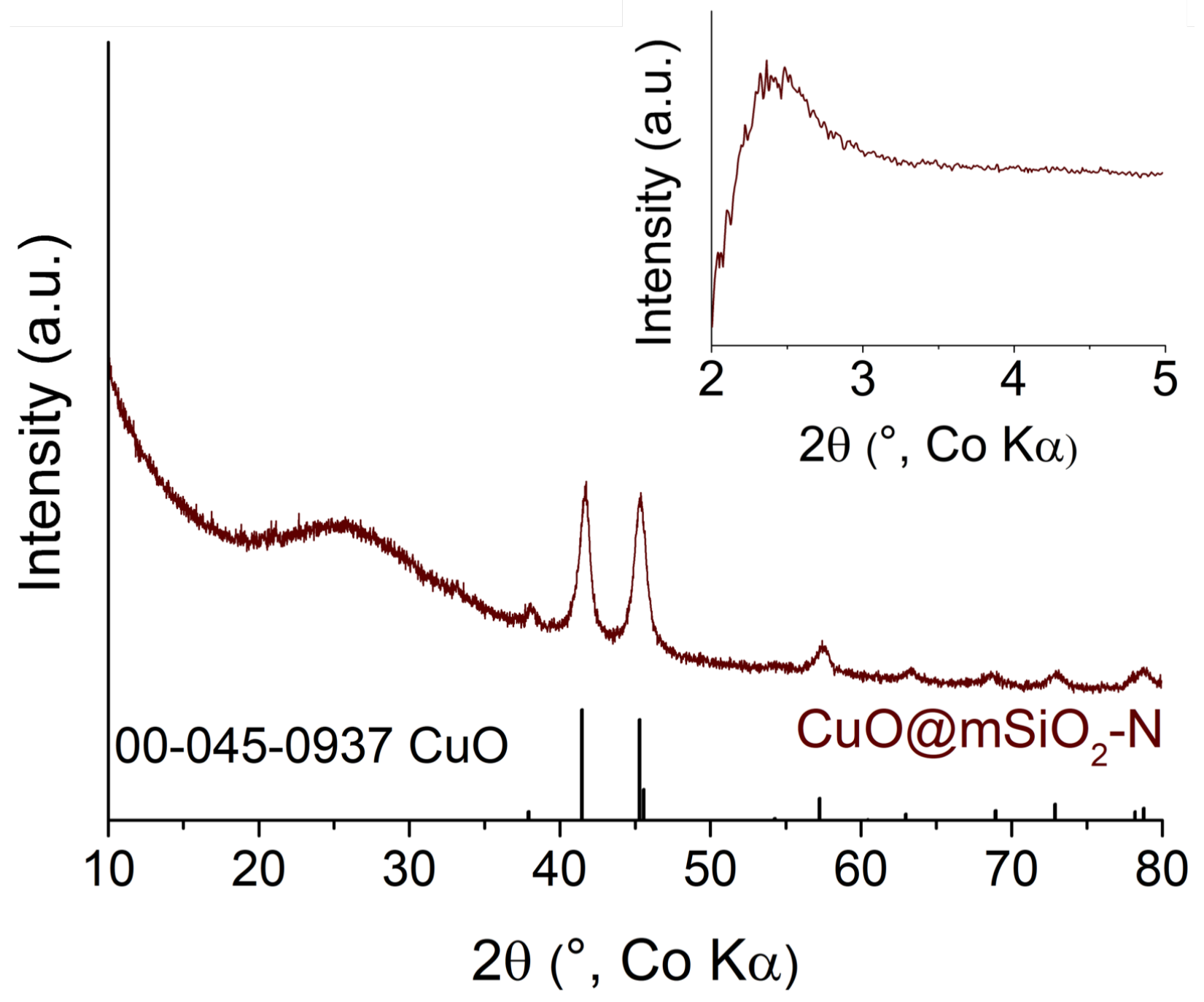

Figure S5. XRD pattern of $\mathrm{CuO} @ \mathrm{mSiO}_{2}-\mathrm{N}$. The inset is the low-angle XRD pattern. (Enlarged version of Figure 1a.) 


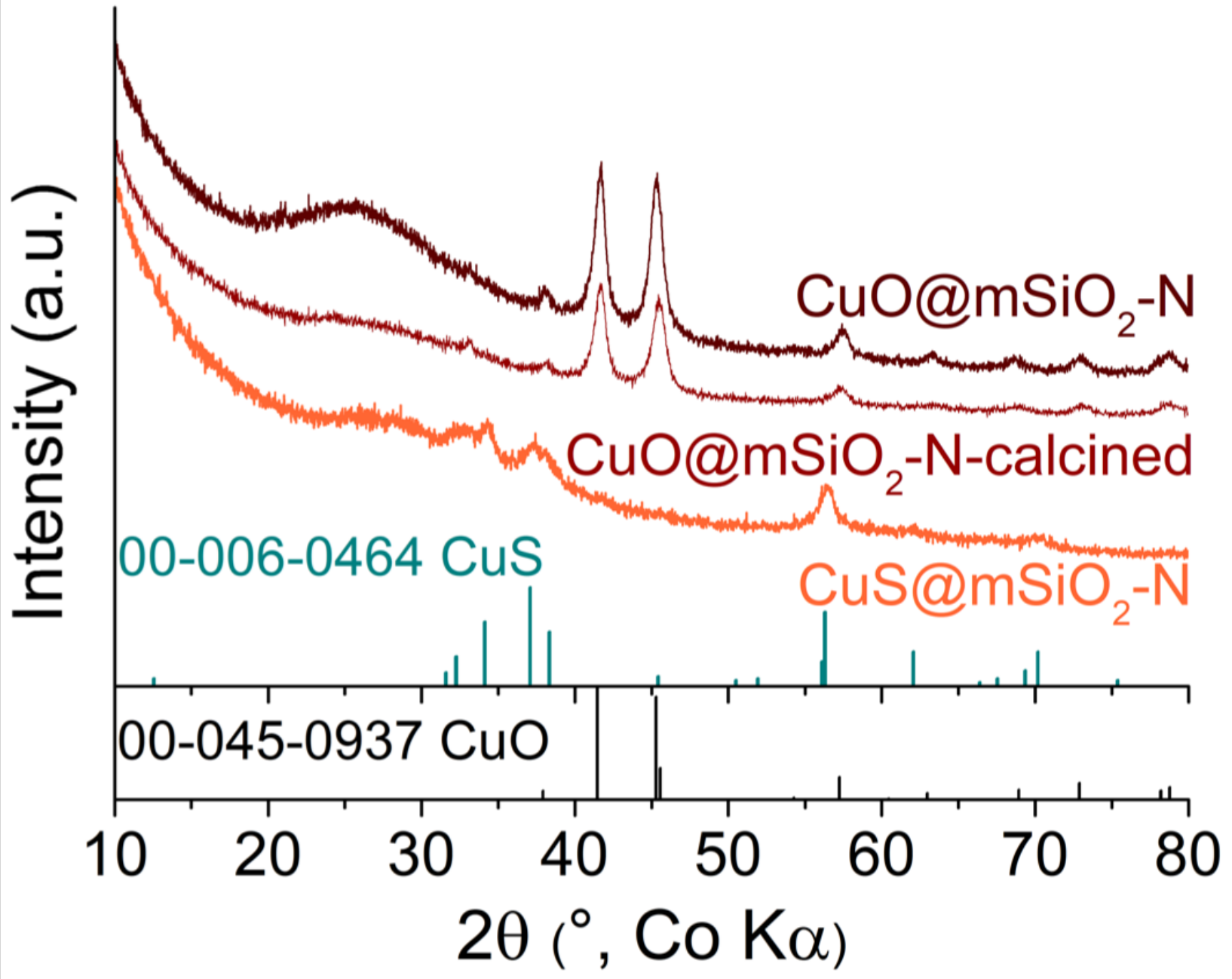

Figure S6. Powder XRD patterns of $\mathrm{CuO} @ \mathrm{mSiO}_{2}-\mathrm{N}$ before and after calcination in air at $350{ }^{\circ} \mathrm{C}$ and of the sulfided material $\mathrm{CuS} @ \mathrm{mSiO}_{2}-\mathrm{N}$. (Enlarged version of Figure 3a.) 

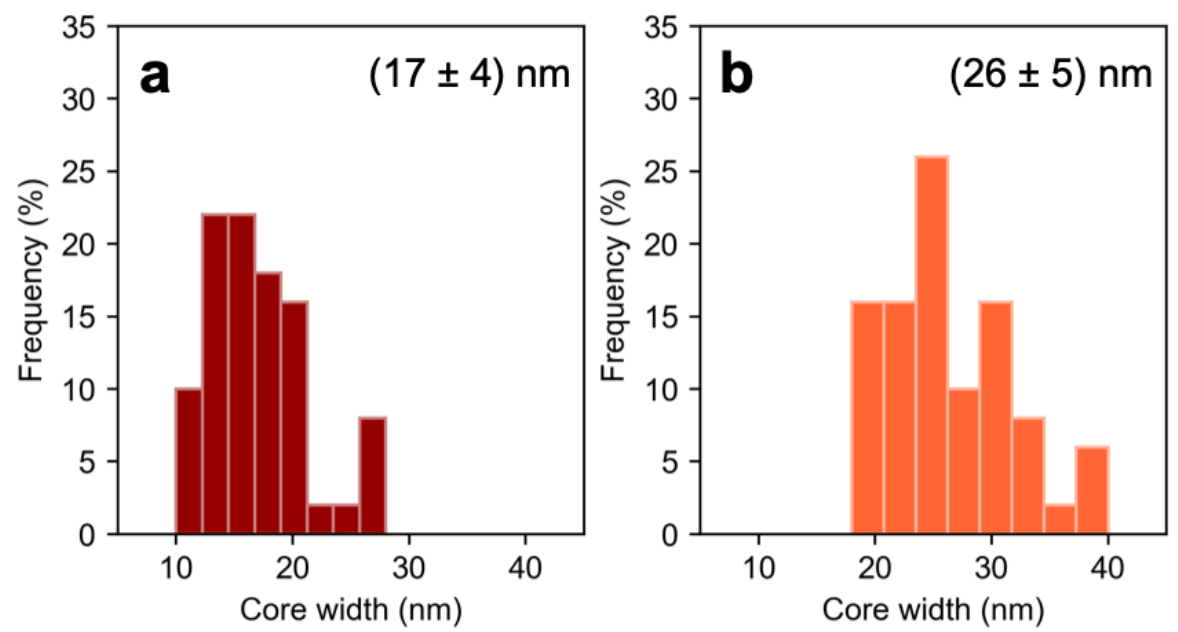

Figure S7. Distributions of core widths of (a) $\mathrm{CuO} @ \mathrm{mSiO}_{2}-\mathrm{N}$-calcined and (b) $\mathrm{CuS} @ \mathrm{mSiO}_{2}-\mathrm{N}$ particles.
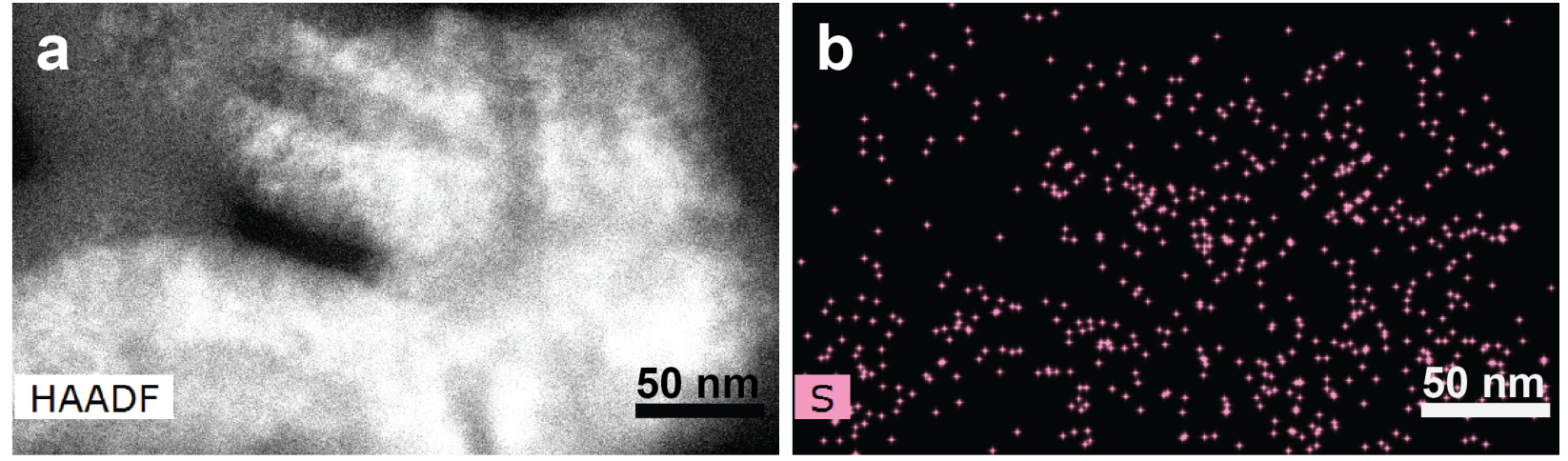

Figure S8. (a) HAADF-STEM image of $\mathrm{CuO} / \mathrm{HmSiO}_{2}-\mathrm{N} 2$ and (b) the corresponding STEM-EDS elemental map for sulfur. 


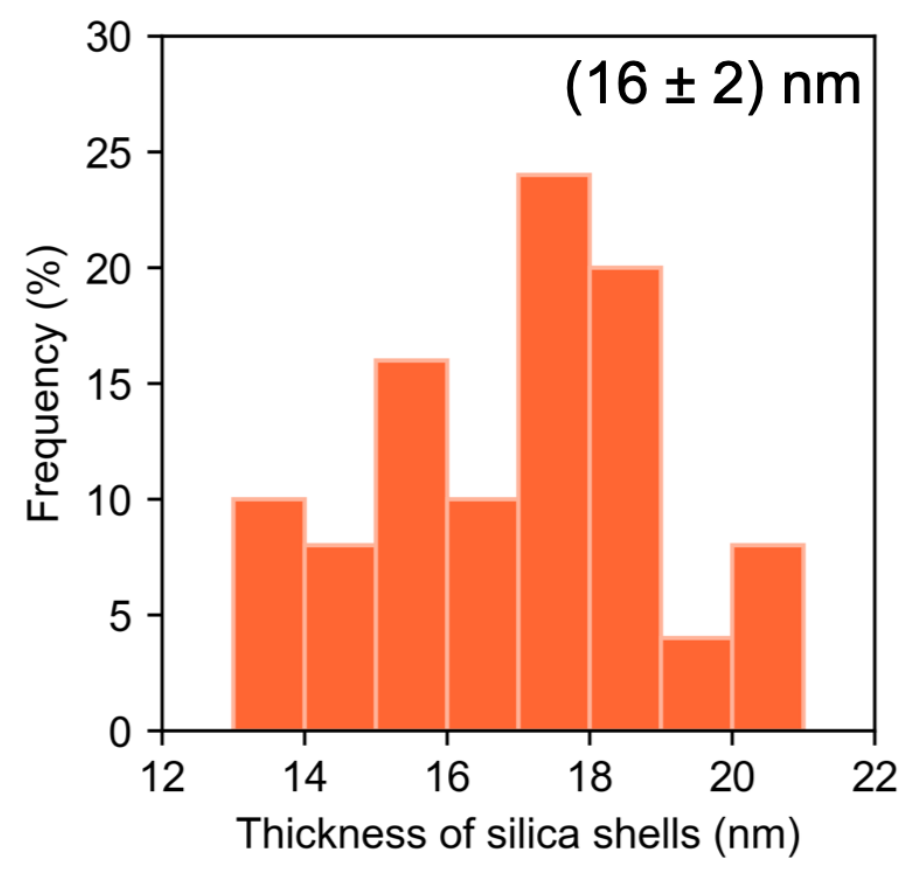

Figure S9. Distribution of the thickness of silica shells of $\mathrm{CuS} @ \mathrm{mSiO}_{2}-\mathrm{D}$ particles.

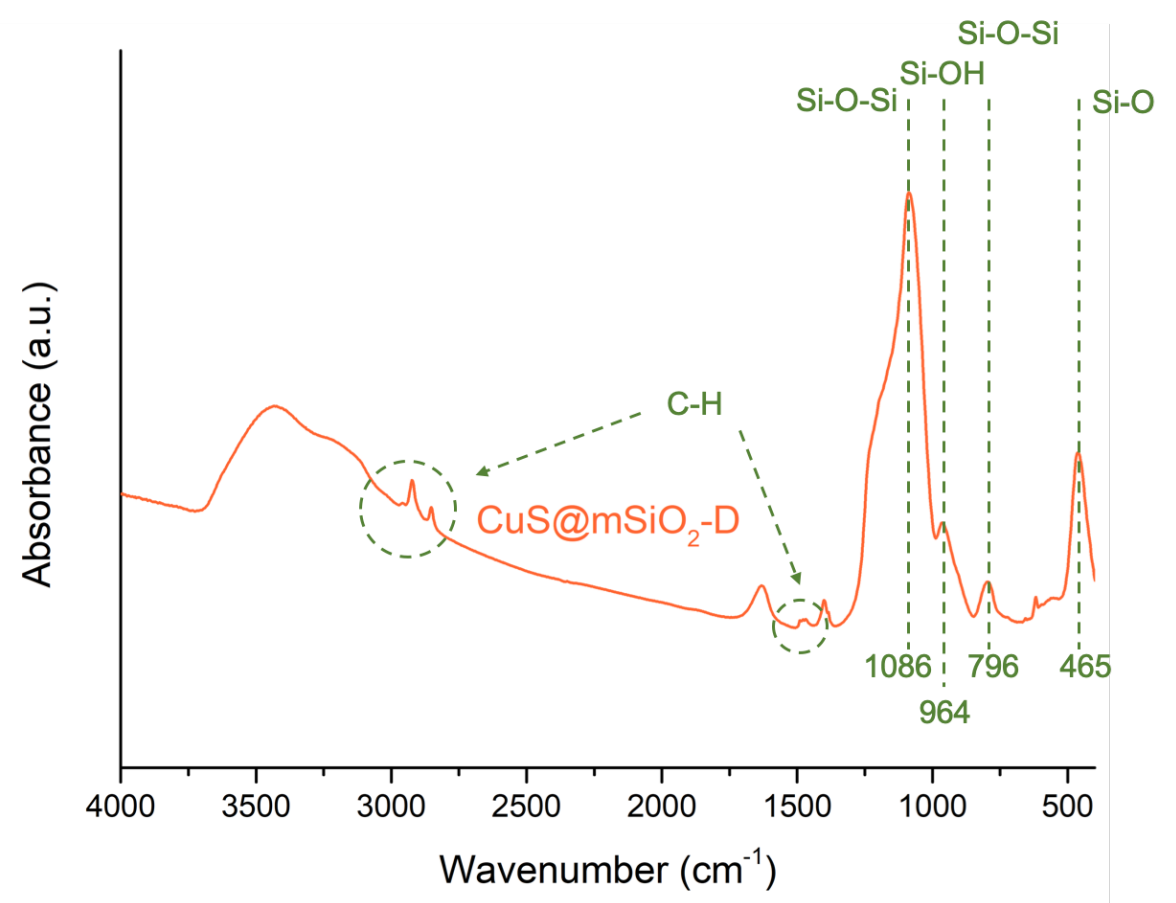

Figure S10. FTIR spectrum of $\mathrm{CuS} @ \mathrm{mSiO}_{2}-\mathrm{D}$. 


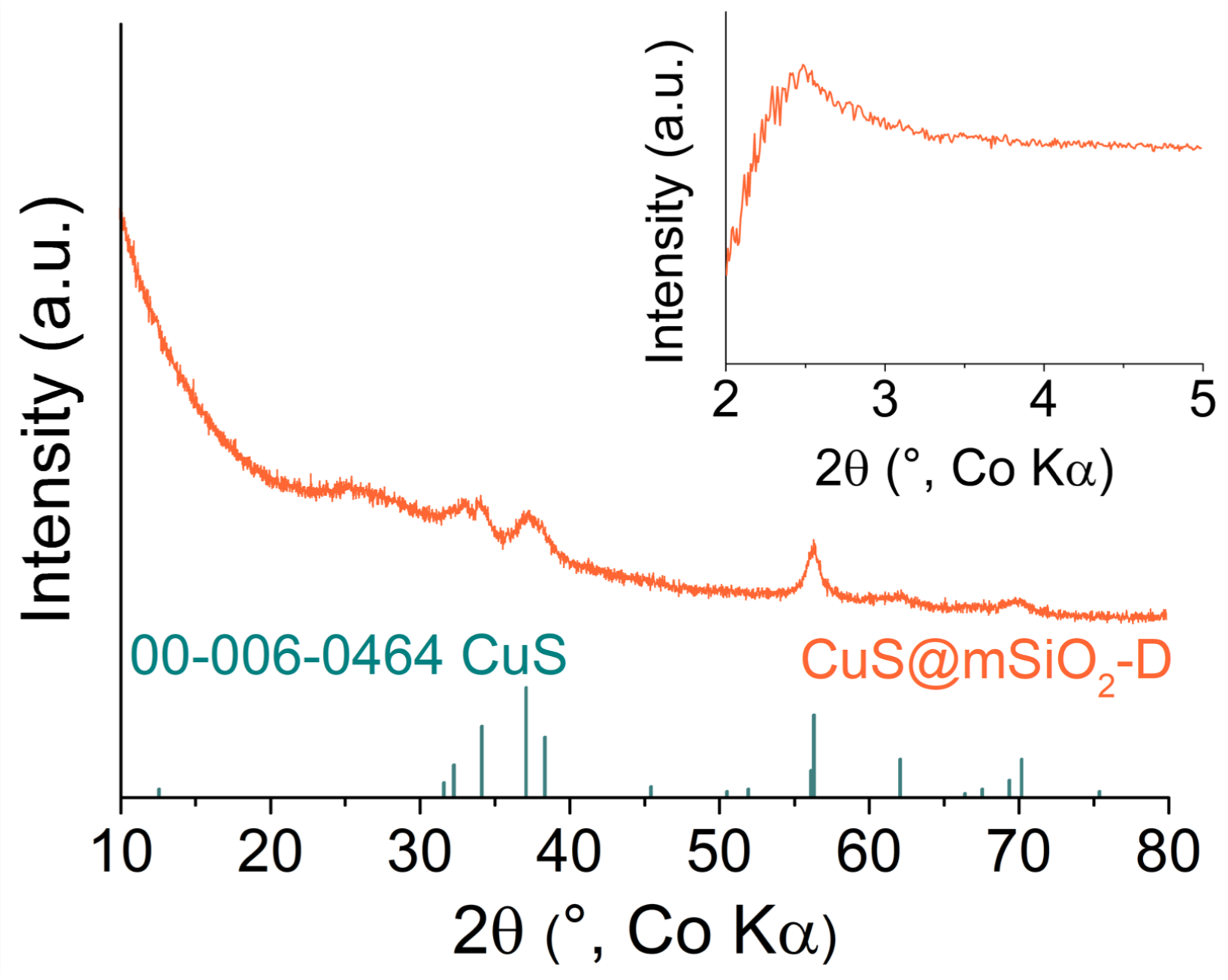

Figure S11. XRD pattern of CuS@ $@ \mathrm{mSiO}_{2}-\mathrm{D}$. The inset is the low-angle XRD pattern. (Enlarged version of Figure 6a.) 

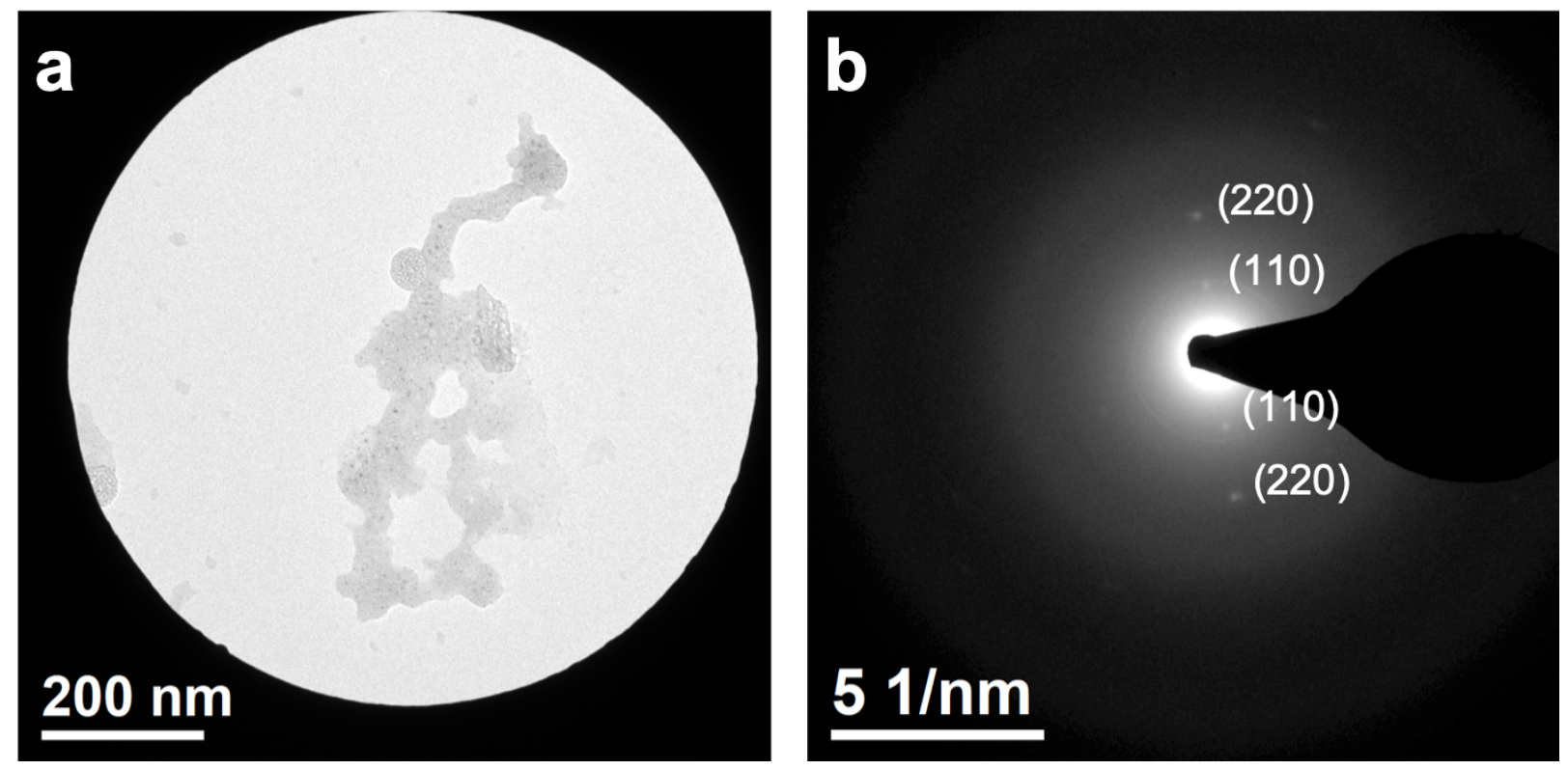

Figure S12. (a) TEM image and (b) SAED pattern of an irregularly-shaped phase observed in the sample $\mathrm{CuS} @ \mathrm{mSiO}_{2}-\mathrm{D}-350$. Reflections in (b) match those of $\mathrm{S}_{8}$ (PDF\# 00-053-1109).

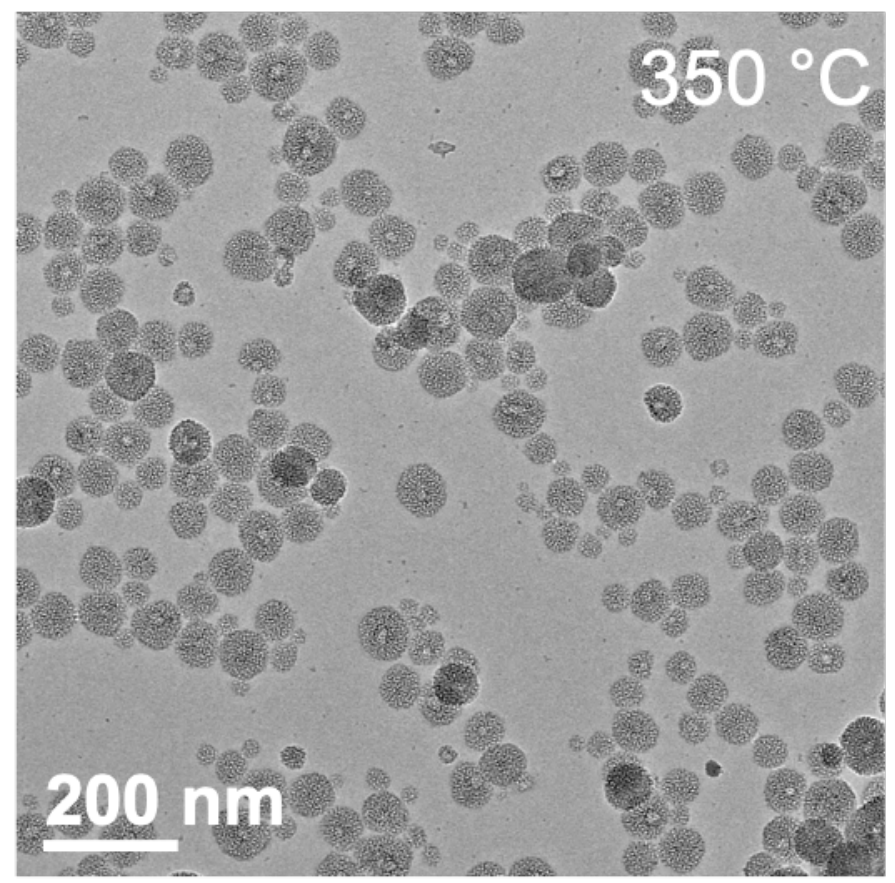

Figure S13. TEM image of $\mathrm{CuS} @ \mathrm{mSiO}_{2}-\mathrm{D}-350$. 